\title{
A comparison of analytical and numerical model predictions of shallow soil temperature variation with experimental measurements
}

\author{
Carlos Naranjo-Mendoza ${ }^{a, b, *}$, Andrew J. Wright ${ }^{b}$, Muyiwa A. Oyinlola ${ }^{b}$, Richard M. Greenough ${ }^{b}$
}

aDepartamento de Ingeniería Mecánica, Escuela Politécnica Nacional, Ladrón de Guevara E11-253, Quito, Ecuador

${ }^{b}$ Institute of Energy and Sustainable Development, De Montfort University, The Gateway, LE1 9BH, Leicester, UK

*corresponding autor: carlos.naranjo@epn.edu.ec

\begin{tabular}{|llll|}
\hline \multicolumn{2}{|c|}{ Nomenclature } & $L E$ & evaporation heat $\left[\mathrm{W} / \mathrm{m}^{2}\right]$ \\
$\alpha$ & thermal diffusivity $\left[\mathrm{m}^{2} / \mathrm{s}\right]$ & $L R$ & long wave radiation $\left[\mathrm{W} / \mathrm{m}^{2}\right]$ \\
$\delta$ & penetration depth $[\mathrm{m}]$ & $R_{n}$ & net radiation $\left[\mathrm{W} / \mathrm{m}^{2}\right]$ \\
$\varepsilon$ & emissivity & $P$ & rainfall $[\mathrm{mm} / \mathrm{s}]$ \\
$\varphi$ & phase angle $[\mathrm{rad}]$ & $S R$ & short wave radiation $\left[\mathrm{W} / \mathrm{m}^{2}\right]$ \\
$\gamma$ & psychometric constant & $T$ & temperature $\left[{ }^{\circ} \mathrm{C}\right]$ \\
$\rho$ & density $\left[\mathrm{kg} / \mathrm{m}^{3}\right]$ & $a b s$ & soil absorptivity \\
$\sigma$ & Stephan-Boltzmann constant $\left[\mathrm{kg} / \mathrm{m}^{3}\right]$ & $c_{p}$ & specific heat $\left[\mathrm{J} / \mathrm{kg}^{\circ} \mathrm{C}\right]$ \\
$\omega$ & angular frequency $[\mathrm{rad} / \mathrm{time}]$ & $e_{a}$ & actual vapour pressure $[\mathrm{kPa}]$ \\
$\Delta T$ & temperature difference $\left[{ }^{\circ} \mathrm{C}\right]$ & $e_{S}$ & saturation vapour pressure $[\mathrm{kPa}]$ \\
$E$ & evaporation rate $\left[\mathrm{kg} / \mathrm{m}^{2} \mathrm{~s}\right]$ & $k$ & thermal conductivity $[\mathrm{W} / \mathrm{mK}]$ \\
$E_{p}$ & evaporation potential rate $\left[\mathrm{kg} / \mathrm{m}^{2} \mathrm{~s}\right]$ & $m$ & node element \\
$F O$ & Fourier number & $p$ & time element \\
$G$ & ground surface heat flux $\left[\mathrm{W} / \mathrm{m}^{2}\right]$ & $q^{\prime \prime}$ & heat flux $\left[\mathrm{W} / \mathrm{m}^{2}\right]$ \\
$H$ & convection $\left[\mathrm{W} / \mathrm{m}^{2}\right]$ & $r$ & aerodynamic resistance \\
$I$ & solar radiation $\left[\mathrm{W} / \mathrm{m}^{2}\right]$ & $t$ & time $[\mathrm{s}]$ \\
$K$ & von Karman constant & $u$ & wind speed $[\mathrm{m} / \mathrm{s}]$ \\
$L$ & latent heat of vaporization $[\mathrm{J} / \mathrm{kg}]$ & $Z$ & depth $[\mathrm{m}]$ \\
& & & \\
Subscripts & & \\
$a$ & air & $o$ & initial \\
$d$ & daily & $s$ & soil \\
$g r$ & ground & inlet & surroundings \\
in & in & stored \\
$m$ & measurement height & out & outlet \\
\hline
\end{tabular}

\section{Abstract}

In several fields of enquiry such as geothermal energy, geology and agriculture, it is of interest to study the thermal behaviour of shallow soils. For this, several analytical and numerical methodologies have been proposed to analyse the temperature variation of the soil in the short and long term. In this paper, a comparative study of different models (sinusoidal, semi-infinite and finite difference method) is conducted to estimate the shallow soil temperature variation in the short and long term. The models were compared with hourly experimental measured data of soil temperature in Leicester, UK, at depths between 0.75 and 2.75 metres. The results show that the sinusoidal model is not appropriate to evaluate the short-term temperature variations, such as hourly or daily fluctuations. Likewise, this model is highly affected by the undisturbed ground temperature and can lead to very high errors. Regarding the semi-infinite model, it is accurate enough to predict the short-term temperature variation. However, it is useless to predict the long-term variation at depths greater than 1 meter. The 
finite difference method (FDM) considering the air temperature as a boundary condition for the soil surface is the most accurate approach for estimating both short and long-term temperature variations while the FDM with heat flux as boundary condition is the least accurate approach due to the uncertainty of the assumed parameters. The ranges of errors for the sinusoidal, semi-infinite and FDM are found to be from 76.09 to $142.13 \%, 12.11$ to $104.88 \%$ and 1.82 to $28.14 \%$ respectively.

\section{Keywords}

Soil, finite difference, heat diffusion, ground, geothermal.

\section{Introduction}

The thermal behaviour of the shallow soil has been of great interest in different research fields such as agriculture [1], geology [2], low enthalpy geothermal energy [3]. The last of these has been of particular interest in recent years due to the increasing use of geothermal heat pump systems for heating and cooling applications. In the case of conventional geothermal heat pump systems, the soil is considered to be a stable and homogeneous medium [4]. This assumption is valid at depths where the ground temperature is undisturbed, usually at a depth greater than 30 metres [5]. However, for systems that feature shallow boreholes or horizontal ground heat exchangers (sometimes called 'slinkies'), seasonal variations as well as changes in the soil temperature in the short term (daily or weekly variations) cannot be neglected. Such systems are usually installed at depths no greater than 5 metres, where they are highly influenced by environmental conditions such as ambient temperature, solar radiation, rainfall and groundwater flows [6]. Therefore, models that accurately predict the influence of these factors, to estimate the thermal behaviour of the soil at different depths over time, should be considered. For this purpose, physical (analytical or numerical) or empirical models can be used. Physical models consider the mechanisms of heat or heat-moisture transfer between the soil and the environment [1] and can be adapted to different locations, soil typologies and environmental conditions. Empirical models are based on correlations from experimental data or time series modelling, are simpler to apply but not always adaptable to different soil typologies or environmental conditions [7]. To develop accurate time series models a large data set of input data is required [8]. For this reason, physics models are preferred for shallow geothermal applications as usually large datasets are unavailable.

\subsection{Analytical physical models}

Several studies using analytical physical models have considered the soil temperature to have a harmonic (sinusoidal) variation over time [9]. For instance, one of the most accepted sinusoidal models is that of Kusuda and Achenbach [10]. This approach is most accurate at depths where shortterm (hourly and daily) changes in the soil's thermal behaviour can be neglected, which is generally at depths greater than $1 \mathrm{~m}$. Likewise, the semi-infinite solid model [11] can be used to study transient phenomena in solids where the heat diffusion is predominantly one dimensional. This model is accurate to study short-term variations in the soil temperature but only at very shallow depths (no more than a few centimetres).

Several studies have proposed different models to estimate the variation of soil temperature. For example, Charpin et al. [12] performed an analytical study using a sinusoidal harmonic model of the heat transfer in a concrete block exposed to the environment. In their study, the authors used the soil surface exposed to a heat flux that includes solar radiation and convection, as a boundary condition. They used the harmonic model to define the variation of ambient air temperature. The authors report that, for a one-day period, the concrete block shows variations in its temperature up to a depth of 20 $\mathrm{cm}$ (thermal penetration depth). The model did not allow accurate predictions of the hourly 
temperature variation but was suitable for a first estimation although the results of the model were not experimentally validated. Likewise, Cleall et al. [13] proposed an analytical model to estimate the soil temperature based on harmonic variations of global solar radiation and ambient temperature. The resolution of the analytical model was compared with a numerical model showing an acceptable match. Although obtaining the analytical solution is complex, the implementation of the final model is simple, and its calculation is fast. This model serves to accurately estimate the thermal behaviour of the soil, although short-term variations cannot be estimated given the harmonic principle of the model. The harmonic model correlated well $\left(R^{2}=0.96\right)$ with the experimental data at a depth of $1 \mathrm{~m}$ however the correlation was poor $\left(R^{2}=0.63\right)$ at a depth of $0.025 \mathrm{~m}$ since short-term variations are not represented well by a harmonic function. In another study, Badache et al. [14] propose an analytical model, based on the Kusuda and Achenbach model, in which the boundary condition is a surface temperature value determined by an empirical model. This method reduces the complexity in obtaining the analytical solution. The model was validated with monthly experimental data from three different locations at depths between 0.1 and 4 metres. The validation shows a good correlation with a root mean square error (RMSE) of $2.5 \mathrm{~K}$ in the worst case at $1 \mathrm{~m}$ depth. However, a limitation of this model is its inability to represent the shallow soil behaviour in the short-term (hourly or daily variations). Due to the complexity of the actual interaction between the soil and the environment, analytical models only deal with the heat transfer phenomenon and neglect the moisture transport process.

\subsection{Numerical physical models}

Numerical models are known to be more accurate and robust for the study of different soil typologies and boundary conditions (BC). However, numerical methods are more complex to implement and take longer to solve [7]. Usually, constant surface temperature or constant heat flux [13] are applied as boundary conditions at the soil surface level. For either of these, it is necessary to determine the soil surface temperature which is normally a parameter that cannot be easily determined since conventional meteorological stations do not measure it [15]. To deal with this problem, in some cases, the soil surface temperature can be approximated as the air temperature [12]. As numerical models are able to represent periodic boundary conditions as well as a more realistic approach to the interaction between soil and environment (including heat and moisture transfer), numerical studies have demonstrated a greater accuracy than analytical models for the study of the thermal behaviour of soil. In fact, Yilmaz et al. [16] concluded in their study that analytical models are generally unrealistic for soil temperature prediction. They compared a harmonic model with a numerical model using the finite difference method (FDM) with heat flux at the surface as a boundary condition. This numerical model allowed the short-term fluctuations to be estimated, however the model was not validated with experimental data. Wullschleger et al [1] developed a computational tool that numerically predicts the soil temperature variation. They included heat and moisture transfer phenomena in the model, which required the precipitation or water irrigation in the soil as input data. The model is able to predict hourly temperature variations on a daily basis. However, it lacks experimental validation and requires a large number of input parameters. In the same way, Chalhoub et al. [17] performed a numerical study to estimate the soil temperature using the FDM. In order to improve accuracy, they considered not only the heat diffusion, convection and radiation but also evaporation. They included in their model an approach to calculate the water content in the soil which is variable according to the rainfall rate. In addition, the authors modelled the variable thermal conductivity and thermal capacitance as a function of the soil moisture content. The results of the numerical model were validated experimentally with data monitored at depths from $0.06 \mathrm{~m}$ to $1.5 \mathrm{~m}$. The authors defined the efficiency of the model as the ratio of the residual variance of the model and the variance of the data set; and it ranges from 0.87 to 0.98 . This numerical model is very accurate and can be 
implemented in numerical simulation programs. However, as the model requires a large number of input parameters, its implementation is impractical when insufficient data are available.

\subsection{Empirical models}

Empirical models have been developed through correlations or more complex statistical methods, by using time series input parameters based on experimental data. For example, Kenan Tezcan [18] developed an equation to determine the ground temperature at 1 metre depth in the soil of Turkey. His equation was based on measurements taken at 193 meteorological stations. Nevertheless, his model is only valid to estimate the average annual temperature. In another empirical study, Chow et al. [9] conducted a non-linear multivariate regression to create an empirical model for estimating the soil temperature at different depths in Hong Kong. In their study, the authors emphasize that at depths of up to 3 metres, air temperature is the variable that most affects the thermal behaviour of the soil, whereas variables such as solar radiation, rainfall, relative humidity or wind speed have little or no influence on the soil. Finally, their empirical model was validated with experimental data from two different meteorological stations showing a RMSE from $0.61{ }^{\circ} \mathrm{C}$ to $1.55{ }^{\circ} \mathrm{C}$. This empirical model requires only time, depth and ambient temperature as input parameters, but it is only valid for the soil conditions of Hong Kong. Droulia et al. [7] compared an analytical model based on daily and annual harmonic variations of the air temperature with two semi-empirical models in which they used average values of air temperature and soil surface temperature. The results show that the analytical model is adequate to estimate the average monthly soil thermal behaviour, but it does not represent the short-term variations well. On the other hand, the semi-empirical models show a greater correlation to the shallow soil variation in the short term. However, in both the analytical and the semi-empirical models, the determination of certain input parameters requires complex statistical resolutions. In a similar study, $\mathrm{Hu}$ et al. [19] developed a semi-empirical model to determine the shallow soil temperature. In their study, the input parameters included are air temperature, rainfall, vegetation cover, solar radiation, and water flux density. The results were compared with experimental data monitored from two different locations at three different depths $(5 \mathrm{~cm}, 10 \mathrm{~cm}$ and $20 \mathrm{~cm}$ ) showing a good correlation at all depths studied ( $R^{2}$ between 0.82 and 0.97$)$. However, the use of many variables as input parameters makes this model very complex for a practical application. Most of these empirical models have been developed using time series as input data in the same way as most forecasting models. The development of time series models requires a very large set of input data mainly of daily average ambient temperature [20] but some of them also require the use of a data set of daily average soil temperature [21], [22]. These models have been demonstrated to be very accurate and useful in forecasting. However, most of them are not designed to predict sub-daily temperature fluctuations and their application to different locations would require at least some snapshot measurements of the soil temperature, as stated by Dolschak et al. [21]. For these reasons, the authors did not try to develop empirical models during the research reported in this paper.

There are several solutions of varying complexity for the estimation of the soil temperature from meteorological data. However, there has been no comprehensive comparison of the different methodologies available, which is important in order to evaluate the relationship between accuracy and complexity of any model for practical applications. In this context, the objective of the research reported in this paper is to compare the accuracy of some commonly used models for estimating the soil temperature at different depths. The results of the models are then compared with hourly experimental data. Section 2 describes the energy balance at the soil surface. Section 3 details the different models to be compared. Section 4 contrasts the theoretical models with experimental data. Finally, section 5 gives the main conclusions. 


\section{Energy balance in the soil surface}

The study of heat transfer in the soil can be a very complex task depending on the accuracy required, as well as the depth at which the soil is studied because the ground temperature becomes more stable with depth. This can be seen in Figure 1, which shows the variation of soil temperature at different depths. The data in Figure 1 were obtained through monitoring in the soil at the test site in Leicester, UK. The soil temperature was monitored every 15 minutes but averaged hourly as explained in Section 5.1. It is clear that the closer to the ground surface, the more unstable the thermal behaviour of the soil, therefore the thermal performance of shallow soil (depth less than 1 metre) is more difficult to predict. For this reason, it is important to perform an energy balance at the soil surface to have a clear idea of the variables that affect the thermal performance of the sub-surface soil.

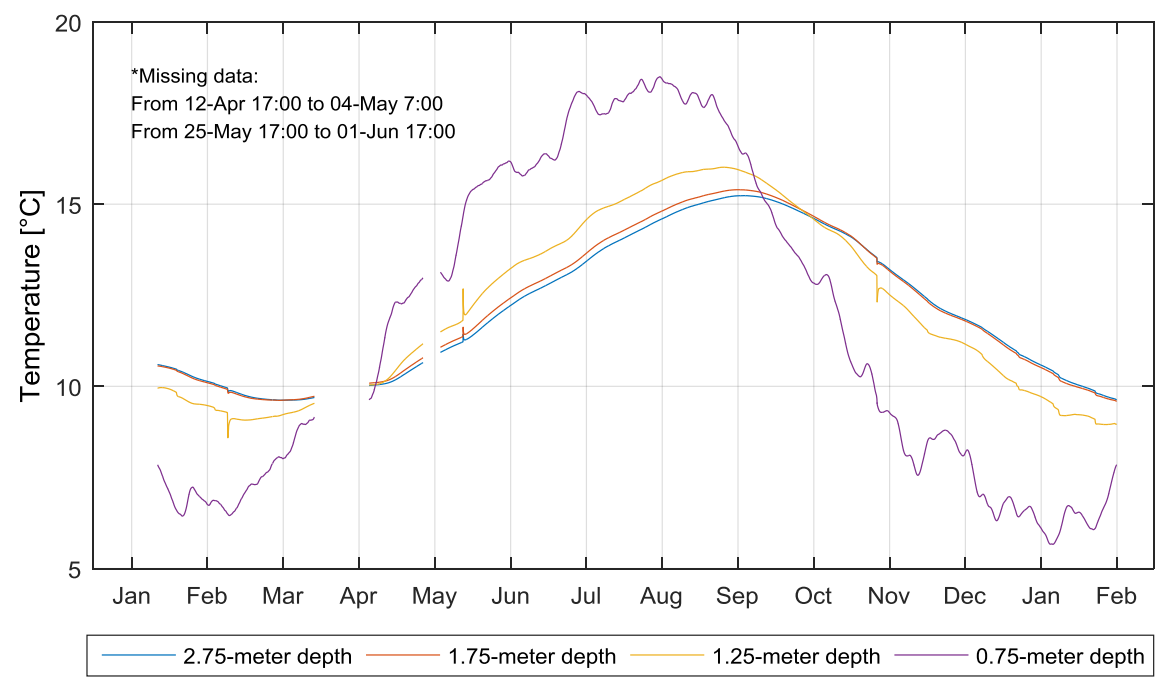

Figure 1. Soil temperature variation with depth

Heat diffusion in soil is a transient phenomenon that can be accurately approximated as a onedimensional flux. Equation 1 (the Fourier heat equation in one dimension) describes this phenomenon and for its resolution, the appropriate temporal and boundary conditions must be considered.

$$
\frac{\partial T}{\partial t}=\alpha \frac{\partial^{2} T}{\partial z^{2}}
$$

Typically, the soil is considered to be a semi-infinite medium and the boundary conditions are as follows:

$T(z, 0)=T_{o}$

$T(0, t)=T_{s}(t)$ or $q_{o}{ }^{\prime \prime}(0, t)=G(t)$

$T(\infty, t)=T_{o}$

where $T(z, t)$ is the temperature of the soil at any depth and time; $T_{o}$ is the initial soil temperature; $T_{S}(t)$ is the soil surface temperature which is highly variable over time, $q_{o}{ }^{\prime \prime}$ is the conduction heat flux and $G(t)$ is the soil surface heat flux which is also variable according to the weather conditions.

If there are no soil surface temperature measurements, the surface soil temperature can be approximated by the air temperature. However, a more accurate calculation involves an analysis of 
heat transfer at the ground surface. Figure 2 shows the main heat transfer mechanisms involved in the ground surface and Equation 2 shows the existing energy balance.

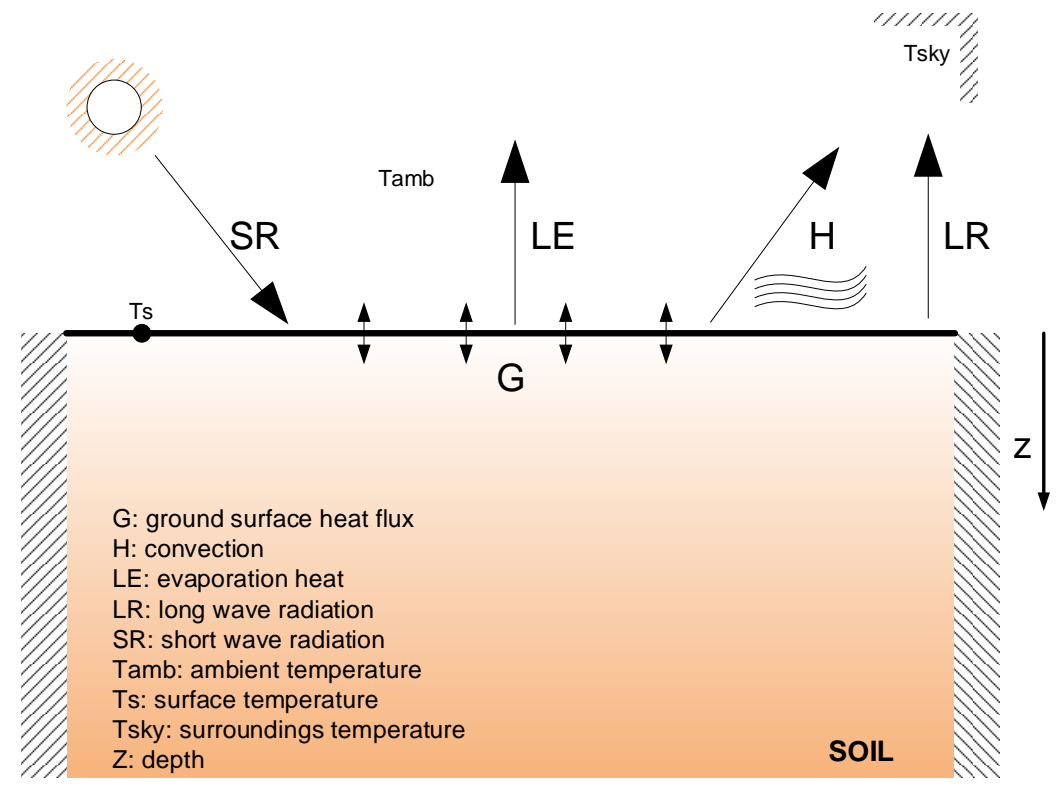

Figure 2. Energy balance in the soil surface

$$
S R-H-L R-L E-G=0
$$

The solution of this energy balance determines the boundary condition at the ground surface, to be applied in Equation 1. Two boundary conditions are commonly used. The first is to consider the ground surface temperature $T_{S}$ as a constant and the second is to consider the heat flux at the ground surface $G$ as a constant. It is important to note that such boundary conditions are considered constant only during a given time step, but they are dynamically or periodically variable. For the case of hourly numerical modelling, as proposed in this study, boundary conditions vary periodically every hour.

In Equation 2, SR refers to the short-wave incident radiation (Equation 3):

$$
S R=a b s \cdot I
$$

where $a b s$ is the soil absorptivity and $I$ is the incident solar radiation.

$H$ is the sensible heat by convection (Equation 4) [17]:

$$
H=\rho_{a} c_{a} \cdot \frac{\left(T_{s}-T_{a}\right)}{r_{a}}
$$

where $\rho_{a}$ is the air density, $c_{a}$ is the air specific heat, $T_{a}$ is the air temperature and $r_{a}$ is the aerodynamic resistance defined by Equation 5 [23]:

$$
r_{a}=\frac{\ln \left(\frac{z_{m}}{z_{o}}\right)}{K^{2} u}
$$

where $z_{m}$ is the standard height of measurement of wind speed ( 2 metres), $z_{o}$ is the roughness length, $K$ is the von Karman constant (0.41) and $u$ is the wind speed.

$L R$ refers to the long-wave radiation exchange with the surroundings (Equation 6):

$$
L R=\varepsilon \sigma\left(T_{s}^{4}-T_{s k y}{ }^{4}\right)
$$


where $\varepsilon$ is the soil emissivity, $\sigma$ is the Stephan-Boltzmann constant $\left(5.67 \mathrm{e}-8 \mathrm{~W} / \mathrm{m}^{2} \mathrm{~K}^{4}\right)$ and $T_{s k y}$ is the sky temperature in $\mathrm{K}$ defined as $0.0552 T_{a}^{1.5}$ [24].

$L E$ is the heat transfer by evaporation (or latent heat) defined by Equation 7:

$$
L E=L \cdot E
$$

where $L$ is the latent heat of evaporation of the water $(2.45 \mathrm{e} 6 \mathrm{~J} / \mathrm{kg})$ and $E$ is the evaporation rate. Before determining $E$, the evaporation rate potential $E_{p}$ must be determined through the PenmanMonteith method (Equation 8) [23].

$$
E_{p}=\frac{1}{L}\left[\frac{\Delta\left(R_{n}-G\right)+\frac{\rho_{a} c_{a}\left(e_{s}-e_{a}\right)}{r_{a}}}{\Delta+\gamma}\right]
$$

where $R_{n}$ is the net radiation flux $(S R-L R), \gamma$ is the psychrometric constant $(\sim 0.066), e_{S}$ is the saturation vapour pressure, $e_{a}$ is the actual vapour pressure and $\Delta$ is the slope of the saturation vapour pressure curve. These three variables can be determined following the Penman-Monteith method as stated in the work of Chalhoub et al. [17]. Then, $E$ can be determined as a function of the rainfall $P$. If $P>E_{p}$ then $E=E_{p}$. If $P<E_{p}$, then $E$ must be determined as stated in Equation 9 . The term $\beta_{d}$ is function of the soil water content. The complete soil water balance and the evaporation model can be found in detail in the work of Chalhoub et al. [17].

$$
E=P+\beta_{d}\left(E_{p}-P\right)
$$

Finally, $G$ is the heat transfer from the soil to the air at the ground surface. The solution of Equation 2 is an iterative process where the results of the surface temperature during a given time step affect the calculation of the surface heat flux during the following time step because convection $H$, evaporation $L E$ and long-wave radiation $L R$ all depend on the soil temperature at the ground surface.

\section{Analytical models for soil temperature calculation}

Analytical models are available to estimate the temporal variation of the soil temperature at different depths. The advantage of analytical models is their simple application and quick computation. In this part, the two most commonly used analytical models for the study of heat diffusion in the soil are described: the sinusoidal model and the semi-infinite solid model.

\subsection{Sinusoidal model}

An example of a sinusoidal model is that of Kusuda and Achenbach [10], [14], which can be used to solve Equation 1 assuming that the surface temperature of the soil has a sinusoidal variation throughout the year. This approximation enables quite an accurate derivation of the average temperature of the soil surface or an evaluation of the temperature of very deep soil (more than 2 metres). However, this analytical model lacks precision if used to evaluate the temperature of very shallow soil (less than one metre deep) or to study the soil at sub-daily time steps, due to the sinusoidal shape of the function. This model only considers the one temperature amplitude (annual or daily) which is inadequate when studying sub-daily temperature fluctuations in very shallow soil.

The boundary condition of the soil surface temperature with sinusoidal variation is shown in Equation 10.

$$
T_{s}(0, t)=\left(\bar{T}_{s}-\Delta T\right) \cdot \cos \left(\omega t-\varphi_{s}\right)
$$


Considering this boundary condition, the resolution of Equation 1, which can be used to determine the temperature at any time and depth, is expressed in Equation 11:

$$
T_{S}(z, t)=\left(\bar{T}_{S}-\Delta T\right) \cdot e^{-z \sqrt{\frac{\omega}{2 \alpha}}} \cdot \cos \left(\omega t-\varphi_{s}-\left(\sqrt{\frac{\omega}{2 \alpha}}\right) z\right)
$$

where $T_{S}(z, t)$ is the soil temperature at any depth $z$ and time $t, \bar{T}_{S}$ is the average annual temperature of the soil surface (equivalent to the undisturbed ground temperature), $\Delta T$ is the average annual amplitude of the surface soil temperature, $\omega$ is known as the annual angular frequency and is equal to $\frac{2 \pi}{t}, \alpha$ is the soil thermal diffusivity and $\varphi_{s}$ is the phase angle in radians and corresponds to the time of the year in which the surface soil temperature is minimal [10], [14].

Thus, to work with the sinusoidal analytical model, prior knowledge of $\bar{T}_{S}, \Delta T, \alpha$ and $\varphi_{S}$ is required. Normally, this model is used to determine the annual behaviour of the soil, however, the same model can be used to determine the daily behaviour. In this case $\overline{T_{S}}$ corresponds to the average daily surface soil temperature, $\Delta T$ to the daily amplitude of the surface soil temperature, $\omega$ is the daily angular frequency and $\varphi_{s}$ is the phase angle which corresponds to the time of day when the temperature of the soil surface is minimal.

Figure 3 shows the variation of the temperature for soil with thermal diffusivity of $6.95 \times 10^{-7} \mathrm{~m}^{2} / \mathrm{s}$; average temperature of $12.5^{\circ} \mathrm{C}$, amplitude of $8{ }^{\circ} \mathrm{C}$ and phase angle of $2 \pi^{*} 31 / 365 \mathrm{rad}$. These input parameters were estimated from measured data (see Section 5.1). As can be seen in the figure, at lower depths the soil temperature is less variable and that at greater depths there is a phase shift compared to the minimum and maximum temperature at the surface. This behaviour is due to the heat capacity of the soil, and the sinusoidal model is able to represent this. However, at the surface this model does not show the sub-daily temperature oscillation, hence this model is not appropriate for very shallow analysis. In general this model is simple and accurate enough for the modelling of conventional borehole heat exchangers and most thermal simulation programs such as TRNSYS [25], RetScreen [26], DOE-2 [27], EnergyPlus [28], etc. use this type of model to predict soil temperature profiles.

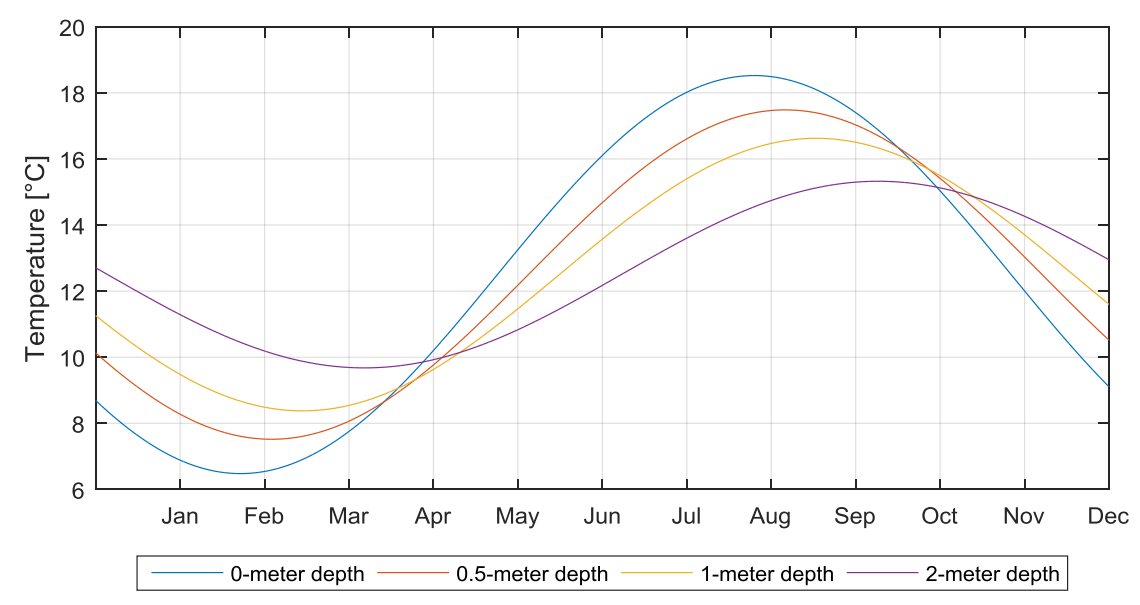

Figure 3. Annual soil temperature variation: sinusoidal model 


\subsection{Semi-infinite solid model}

The semi-infinite solid model [11] is an analytical solution of Equation 1 in which any solid is considered to be an infinite medium in all directions except one (the z-direction). This model is widely used for the study of thin elements like beams and metallic plates, and also for the study of the ground. Analytical solutions of the semi-infinite model are available for three different boundary conditions: constant surface temperature $T_{S}$ (Equation 12), surface exposed to convection and surface exposed to a constant heat flux $q_{o}^{\prime \prime}$ (Equation 13) [11]. The variation in the boundary conditions over time can be treated as a step function.

$$
\begin{gathered}
T(z, t)=\left[\operatorname{erf}\left(\frac{z}{2 \sqrt{\alpha t}}\right) \cdot\left(T_{o}-T_{S}\right)\right]+T_{S} \\
T(z, t)=\left[\frac{2 q_{o}^{\prime \prime}(\alpha t / \pi)^{1 / 2}}{k} \cdot \exp \left(\frac{-\mathrm{z}^{2}}{4 \alpha t}\right)-\frac{q_{o}^{\prime \prime} \mathrm{z}}{k} \cdot \operatorname{erfc}\left(\frac{z}{2 \sqrt{\alpha t}}\right)\right]+T_{o}
\end{gathered}
$$

Where erf is the error function and erfc is the complementary function of error. The analytical semiinfinite solid model is very accurate when analysing the thermal response of a solid with a fixed boundary condition over a given time. However, this model is not appropriate for use with periodic boundary conditions since it does not accumulate the results from previous time steps. For this reason, several authors such as Charpin et al. [12] and Florides and Soteris [29] make use of the 'thermal penetration depth' $\left(\delta_{p}\right)$ which corresponds to the distance over which changes in temperature are evidenced if a boundary condition is applied for a time $t$. In other words, the longer the exposure to a boundary condition, the greater the penetration depth and vice versa. This means that for very variable ambient conditions (hourly time step), temperature changes at depths greater than a few centimetres cannot be seen accurately through this model. Equation 14 shows the thermal penetration depth for a given time $(\omega=2 \pi / t)[30]$.

$$
\delta_{p}=4 \sqrt{\frac{\alpha}{\omega}}
$$

For example, for a soil with thermal diffusivity $\alpha=6.95 \times 10^{-7} \mathrm{~m}^{2} / \mathrm{s}$, the thermal penetration depth for different times of analysis is shown in Table 1. As can be seen, in order to determine the influence of a boundary condition at a depth of 1 metre, the boundary condition must be applied for approximately 150 hours.

Table 1. Thermal penetration depth at different analysis time

\begin{tabular}{c|c}
\hline $\boldsymbol{t}$ (hours) & $\boldsymbol{\delta}_{\boldsymbol{p}}$ (metres) \\
\hline 0 & 0 \\
\hline 1 & 0.05 \\
\hline 15 & 0.3 \\
\hline 40 & 0.5 \\
\hline 157 & 1 \\
\hline 354 & 1.5 \\
\hline 628 & 2 \\
\hline 981 & 2.5 \\
\hline 1413 & 3 \\
\hline
\end{tabular}


Figure 4 shows the stepwise application of the semi-infinite solid model with constant surface temperature for each step as the boundary condition (Equation 12). The boundary condition is variable each hour as a step function since the data from weather stations is normally collected on an hourly basis. This figure clearly shows the concept of the thermal penetration depth (Table 1 ) where for time steps of 1 hour the penetration depth is $5 \mathrm{~cm}$. This means that this model is very accurate to evaluate the temperature variation up to a depth of $5 \mathrm{~cm}$. As the depth increases the accuracy is reduced so that for depths greater than 0.2 metres the model is inappropriate. Note that at depths greater than 0.5 metres, the model output is a horizontal line. At these depths, an approximate solution might be to consider the average temperature over a time step greater than one hour and apply that average temperature as boundary condition. However, this would affect the analysis of the short-term temperature variation.

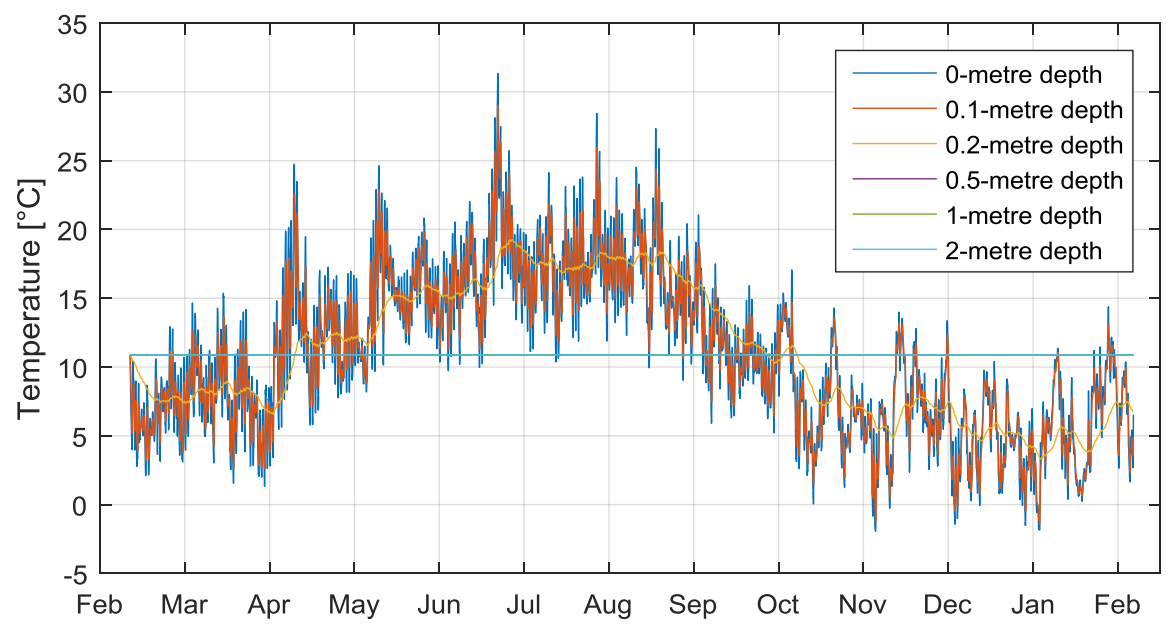

Figure 4. Soil temperature variation: semi-infinite solid model

\section{Numerical model of the finite difference method FDM}

As previously seen, the sinusoidal model accurately represents the thermal behaviour of deep soil but lacks precision for very shallow and short-term analyses. On the other hand, the semi-infinite solid model is more accurate to represent the temperature of shallow soil (of the order of a few centimetres) but lacks precision for deep soil. To increase the range of accurate analysis, the soil can be modelled by the numerical method of finite differences (FDM). This method is widely used for the analysis of complex geometries, and where there are variable boundary conditions. The principle of the method is to numerically solve Equation 1 by dividing the analysis system into a large but finite number of elements or nodes. Then each element is analysed independently in space and time. This method allows for accumulating previous results so is robust for modelling.

In order to discretize Equation 1, the explicit method was used [11]. This method was preferred over the implicit method as it is simpler to formulate and quick enough to compute. Figure 5 shows a schematic of the studied soil divided into $n$ elements of thickness $\Delta z$ along the $z$-direction. The temperature is evaluated in the centre of each node $i$. 


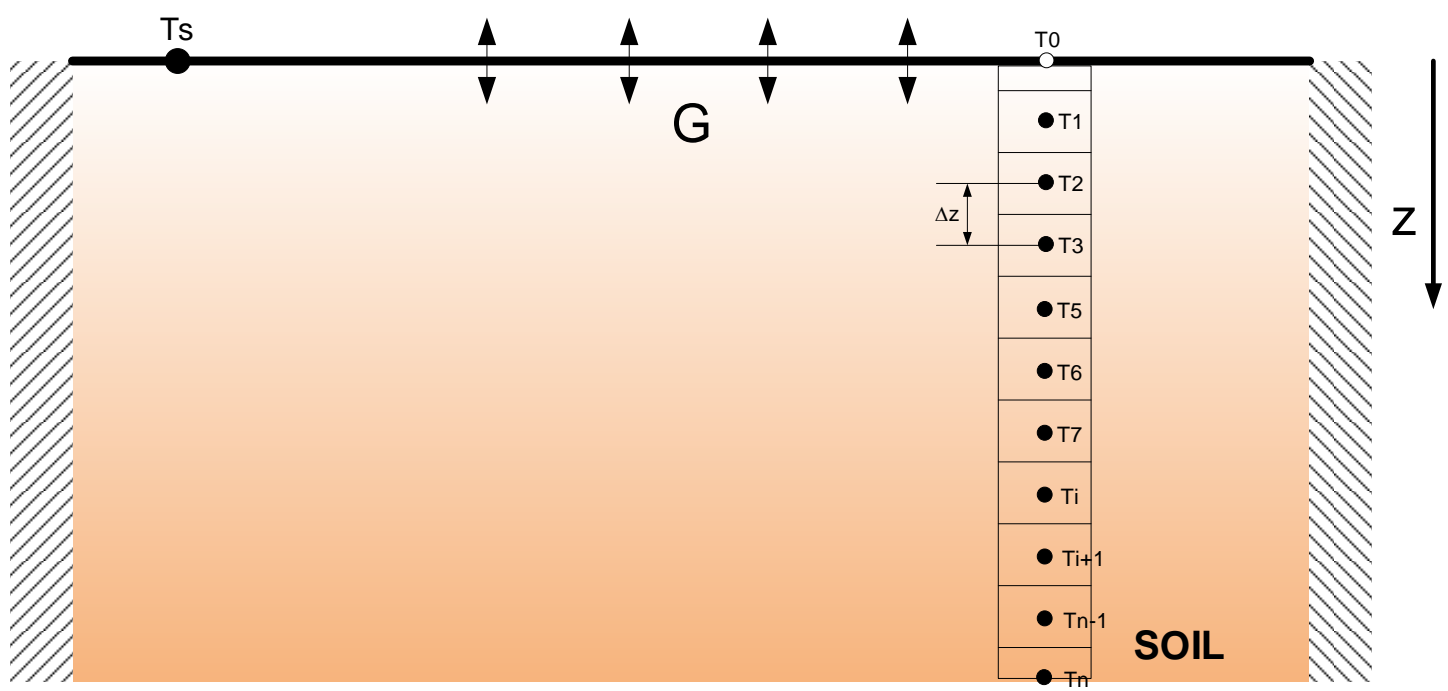

Figure 5. Finite difference representation of the soil

Equation 15 represents the discretization of Equation 1 by the explicit form of the FDM considering one-dimensional heat transfer. Each time step is represented by a number $p$ and $\Delta t$ is the size of the time step, so that $t=p \Delta t$. More information about the equation discretization and the applicability of the FDM can be found in many Heat Transfer textbooks such as Incropera et al. [11].

$$
T_{i}^{p+1}=F o\left(T_{i+1}^{p}+T_{i-1}^{p}\right)+(1-2 F o) T_{i}^{p}
$$

To solve this equation correctly by the explicit method, the stability criterion of Equation 15 is:

$$
(1-2 F o) \geq 0 \text { or } F o \leq \frac{1}{2} \text {. }
$$

Equation 15 is valid for any interior node that does not have internal heat generation. However, for the external nodes, the discretization must be done using an energy balance that considers the boundary conditions to which the external nodes are exposed. In this context, two different boundary conditions were considered: a soil with constant surface temperature (which we will call the FDM-T condition) and a soil with constant surface heat flux (the FDM-HF condition). These boundary conditions are shown in Equations 16 and 17 respectively.

$$
\begin{gathered}
T_{1}=T_{s} \\
T_{1}^{p+1}=\frac{F o \Delta z G}{k_{s}}+F o T_{2}^{p}+(1-F o) T_{1}^{p}
\end{gathered}
$$

Under both boundary conditions the soil was treated as a semi-infinite solid, hence no boundary condition was imposed for the $n^{\text {th }}$ node. In order to deal with the infinite boundary, a depth of 10 meters was chosen for the numerical analysis. 


\section{Comparison with experimental results}

This section compares the different analytical and numerical models with the experimental data from the soil monitored during one year as part of a project to evaluate a soil-based thermal store. The objective is to find the most practical and accurate model for the study of heat diffusion in very shallow soil. Subsequently, the chosen model will be used to study the behaviour of very shallow borehole heat exchangers. The soil temperature sensors for this part of the research are placed far from the thermal store to avoid influencing the readings of the natural soil temperature. The approach used for this study was based on the comparison of two analytical models (sinusoidal and semi-infinite) and a numerical model with two different boundary conditions (FDM-T and FDM-HF) against hourly experimental data. The comparison was carried out using three statistical measures: the coefficient of determination $\left(\mathrm{R}^{2}\right)$, root mean square error (RMSE) and the normalised root mean square error (NRMSE) as shown in the Figure 6.

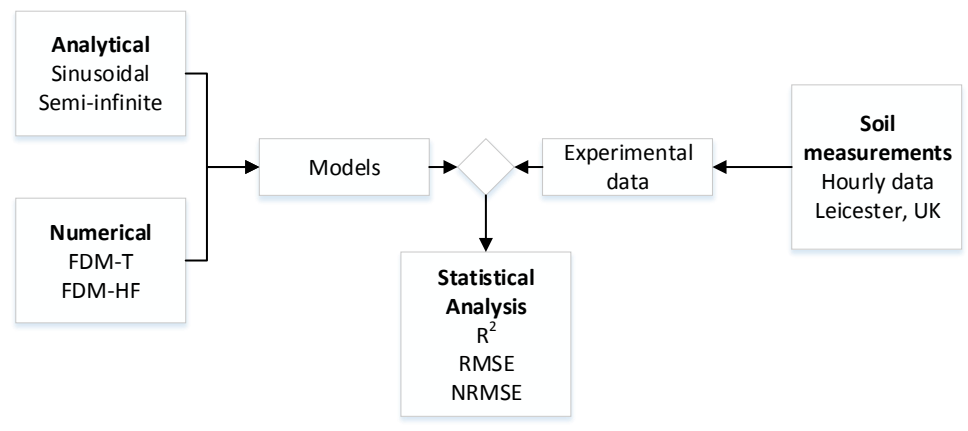

Figure 6. Approach for the comparison analysis

\subsection{Experimental data}

Since $10^{\text {th }}$ February 2016, temperature data have been collected from sensors in grass-covered soil in an urban area located about 2 metres from a university building and a row of houses in Leicester, UK (Figure 7). The depths of measurement are 0.75, 1.25, 1.75 and 2.75 metres. The sensors used for monitoring the soil are PT1000 resistance temperature detector (RTD) sensors. All sensors were calibrated and have an accuracy of $\pm 0.3^{\circ} \mathrm{C}$. Figure 1 shows the data collected which were used to evaluate the predicted temperature variations according to the analytical and numerical models. In addition, Figure 8 shows the temperature profile for 3 representative dates during winter, summer and autumn. The figure includes the ambient temperature values (at $0 \mathrm{~m}$ depth). Note that at a depth of 2.75 metres, the soil cannot be considered undisturbed since it has temporal variation. We can see that a very shallow borehole heat exchanger will be highly influenced by the seasonal thermal variations. 


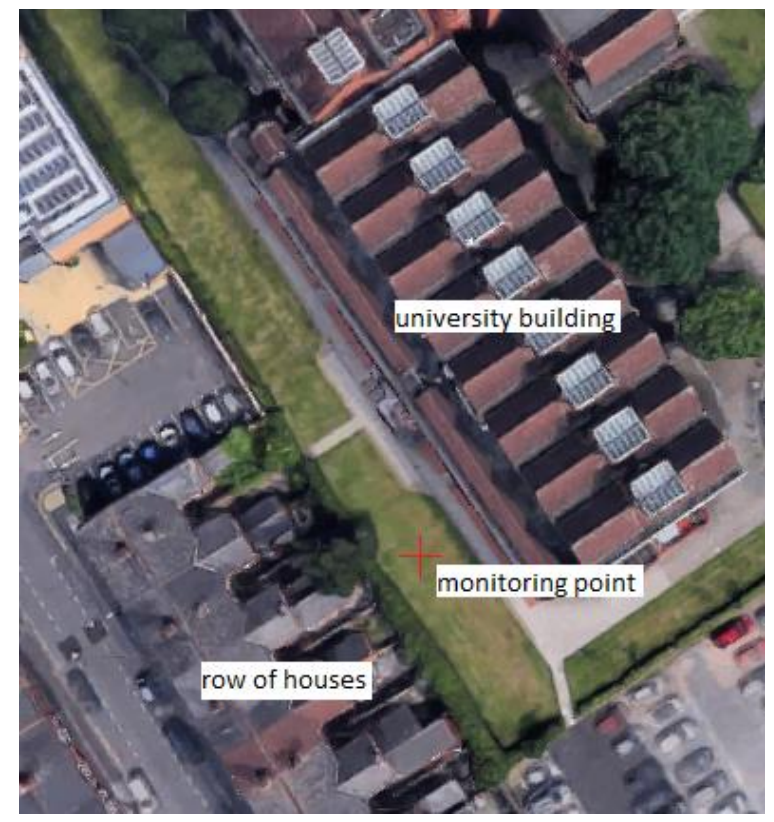

Figure 7. Experimental soil temperature profile

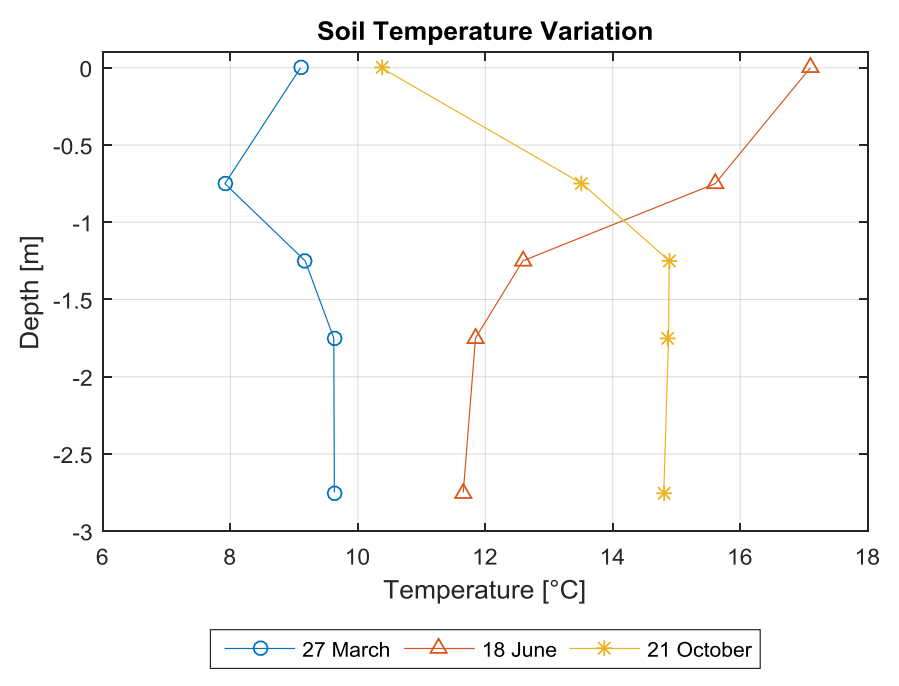

Figure 8. Experimental soil temperature profile

\subsection{Undisturbed ground temperature}

The undisturbed ground temperature is the temperature of the soil at depths where the seasonal variations have no influence. The values of this temperature vary according to the location and the most accurate way to determine this is through experimental measurements of the deep ground. In reality, such experimental measurements can be difficult, so the value of undisturbed temperature may be estimated by different methods. The simplest is to assume that the value of the annual average air temperature matches the undisturbed ground temperature. However, in very variable climates, this assumption may be erroneous [31]. Hence for greater accuracy, the average temperature of the soil surface may be used in place of the average air temperature. The average temperature of the soil surface is not easily available, as conventional weather stations do not usually monitor this parameter. This research uses the correlation model proposed by Badache et al. [31] which allows the undisturbed ground temperature to be estimated from the average ambient temperature using Equation 18: 


$$
T_{g r}=17.898+0.951 T_{a}
$$

where $T_{g r}(\mathrm{~K})$ is the undisturbed ground temperature and $T_{a}(\mathrm{~K})$ is the average air temperature. This model has a coefficient of determination $\left(R^{2}\right)$ of 0.995 verified with experimental values from seventeen different locations around the world.

In the case of the soil in Leicester, UK, the undisturbed ground temperature is $14.87^{\circ} \mathrm{C}$ based on an average annual ambient temperature of $10.88^{\circ} \mathrm{C}$.

Input data for the different analytical and numerical models are shown in Table 2. For all models, the soil was treated as homogenous (constant thermal conductivity and specific heat). A thermal response test was conducted on the site of experimental data collection giving an average thermal conductivity value of $1.47 \mathrm{~W} / \mathrm{mK}$. The thermal response test is the most widely accepted procedure for determining soil thermal properties for shallow applications. This procedure is carried out by monitoring the soil temperature when it is subjected to a constant heat flux [32]. The values of specific heat capacity published in British Guideline MCS MIS 3005 [33] for the soil type in this study (wet clay), were used. It is worth noting that the soil properties vary as a function of the soil water content. Likewise, the soil composition can vary as a function of depth and therefore the soil properties can also vary with the depth [34].

Table 2. Input parameters used for the simulations

\begin{tabular}{|c|c|}
\hline $\begin{array}{l}\text { Analytical Sinusoidal Model } \\
\text { Equation } 11\end{array}$ & $\begin{array}{l}\bar{T}_{s}=14.87^{\circ} \mathrm{C} \\
\Delta T=8{ }^{\circ} \mathrm{C} \\
\alpha_{s}=6.95 \times 10^{-7} \mathrm{~m}^{2} \mathrm{~s}^{-2} \\
\varphi_{s}=\frac{2 \pi \cdot 31}{365} \mathrm{rad}\end{array}$ \\
\hline $\begin{array}{l}\text { Analytical Semi-infinite Model } \\
\text { Equation } 12\end{array}$ & $\begin{array}{l}T_{o}=\text { mean air temperature }{ }^{\circ} \mathrm{C} \\
T_{S}=\text { air temperature }{ }^{\circ} \mathrm{C} \\
\alpha_{S}=6.95 e^{-7} \mathrm{~m}^{2} / \mathrm{s}\end{array}$ \\
\hline $\begin{array}{l}\text { Numerical FDM Surface temperature as BC } \\
\text { (FDM-T) } \\
\text { Equations } 15 \text { and } 16\end{array}$ & $\begin{array}{l}\Delta z=0.075 \mathrm{~m} \\
\Delta t=3600 \mathrm{~s} \\
\alpha_{s}=6.95 \times 10^{-7} \mathrm{~m}^{2} / \mathrm{s} \\
k_{s}=1.5 \mathrm{~W} / \mathrm{mK} \\
T_{s}=\text { air temperature }{ }^{\circ} \mathrm{C} \\
\rho_{s}=1800 \mathrm{~kg} / \mathrm{m}^{3} \\
C p_{s}=1200 \mathrm{~J} / \mathrm{kgK}\end{array}$ \\
\hline $\begin{array}{l}\text { Numerical FDM Surface heat flux as BC } \\
\text { (FDM-HF) } \\
\text { Equations } 15 \text { and } 17\end{array}$ & $\begin{array}{l}\Delta z=0.075 \mathrm{~m} \\
\Delta t=360 \mathrm{~s} \\
\alpha_{s}=6.95 \times 10^{-7} \mathrm{~m}^{2} / \mathrm{s} \\
k_{s}=1.5 \mathrm{~W} / \mathrm{mK} \\
T_{s}=\text { air temperature }{ }^{\circ} \mathrm{C} \\
\rho_{s}=1800 \mathrm{~kg} / \mathrm{m}^{3} \\
C p_{s}=1200 \mathrm{~J} / \mathrm{kgK} \\
G=\text { calculated by solving Equation } 2 .\end{array}$ \\
\hline
\end{tabular}

\subsection{Sinusoidal analytical model}

The sinusoidal model is supposed to be an accurate model for predicting the temperature of deep soil. However, when compared with the experimental data, this model was found to be impractical and highly dependent on the value of the undisturbed ground temperature. In fact, with the calculated 
value of the undisturbed ground temperature $\left(14.87^{\circ} \mathrm{C}\right)$, the model did not match the experimental data as seen in Figure 9. It is noted that the model overestimates the ground temperature at all the assessed depths. This might be due to the uncertainty on the calculated value of the undisturbed ground temperature. Unfortunately, this value is rarely measured by the weather stations and estimations must be done. It is clear to see that the current undisturbed ground temperature may be lower that the predicted by Badache et al. [31] model. However, when not experimental data are available, this value must be determined by means on the ambient air temperature and consequently the uncertainty of the application of this model increases. For this reason, the sinusoidal model should be used carefully as this it is very sensitive to small differences on the input values.
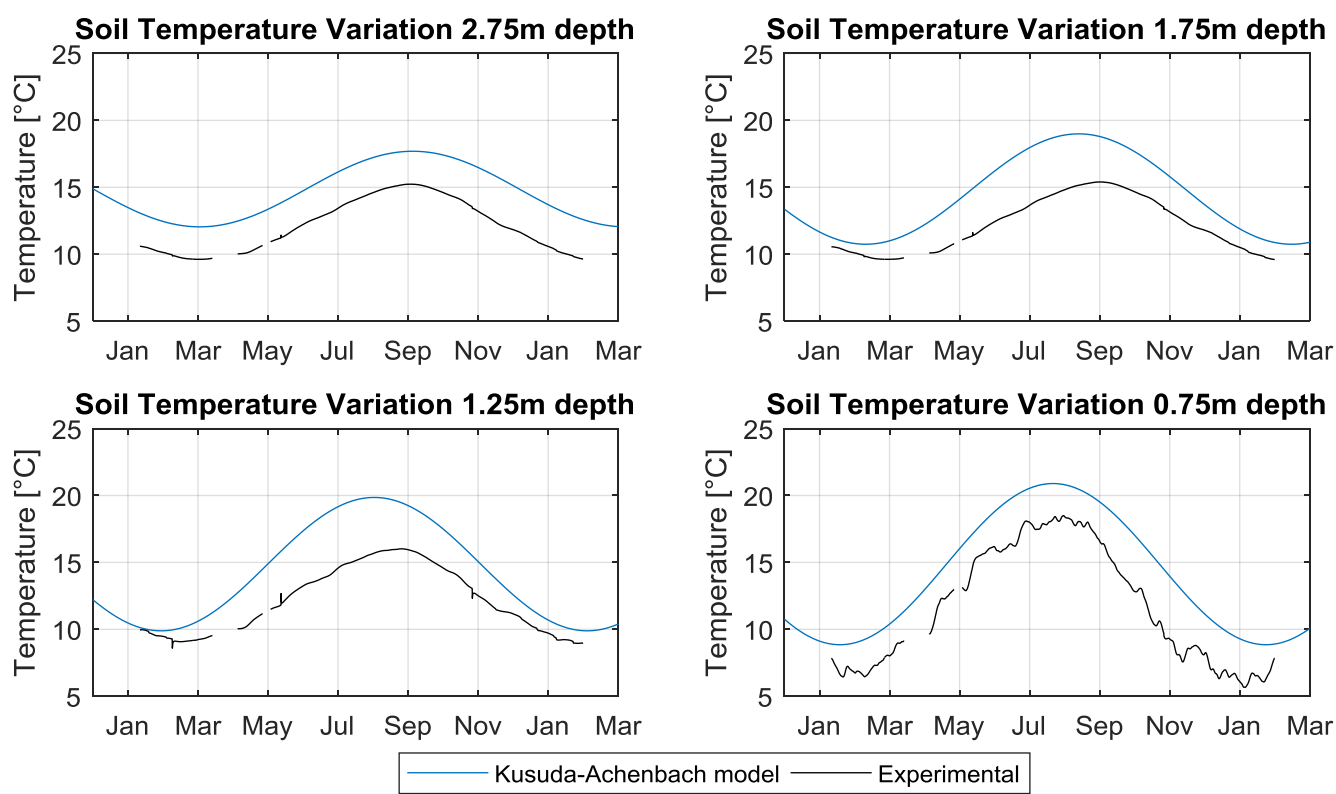

Figure 9. Comparison between the sinusoidal model and experimental data

\subsection{Semi-infinite solid model}

Figure 10 shows the comparison between the experimental data and the predictions of the semiinfinite solid model considering constant surface temperature as a boundary condition. As the depth of analysis increases the accuracy of the model is reduced due to the thermal penetration depth. Hence, the model is more accurate at shallower depths, as previously explained. To increase the accuracy and applicability of this model, the analysis was considered at variable time steps according to the depth (see Section 3.2). For instance, for 0.75 metres, Equation 14 was used to find the minimum analysis time, which was 89 hours. Therefore, the average value of the air temperature was obtained every 89 hours and that value was imposed as a boundary condition for 89 hours. For the analysis at depths of 1.25, 1.75 and 2.75 metres, the minimum times of analysis were 246, 482 and 1188 hours respectively. As can be noted, for larger depths, the minimum analysis time was increased to very high values and consequently the correlation against experimental data is reduced.

From the above, it is seen that this model is accurate enough to predict the temperature of very shallow soil (depths less than $1 \mathrm{~m}$ ) but loses accuracy at greater depths. 

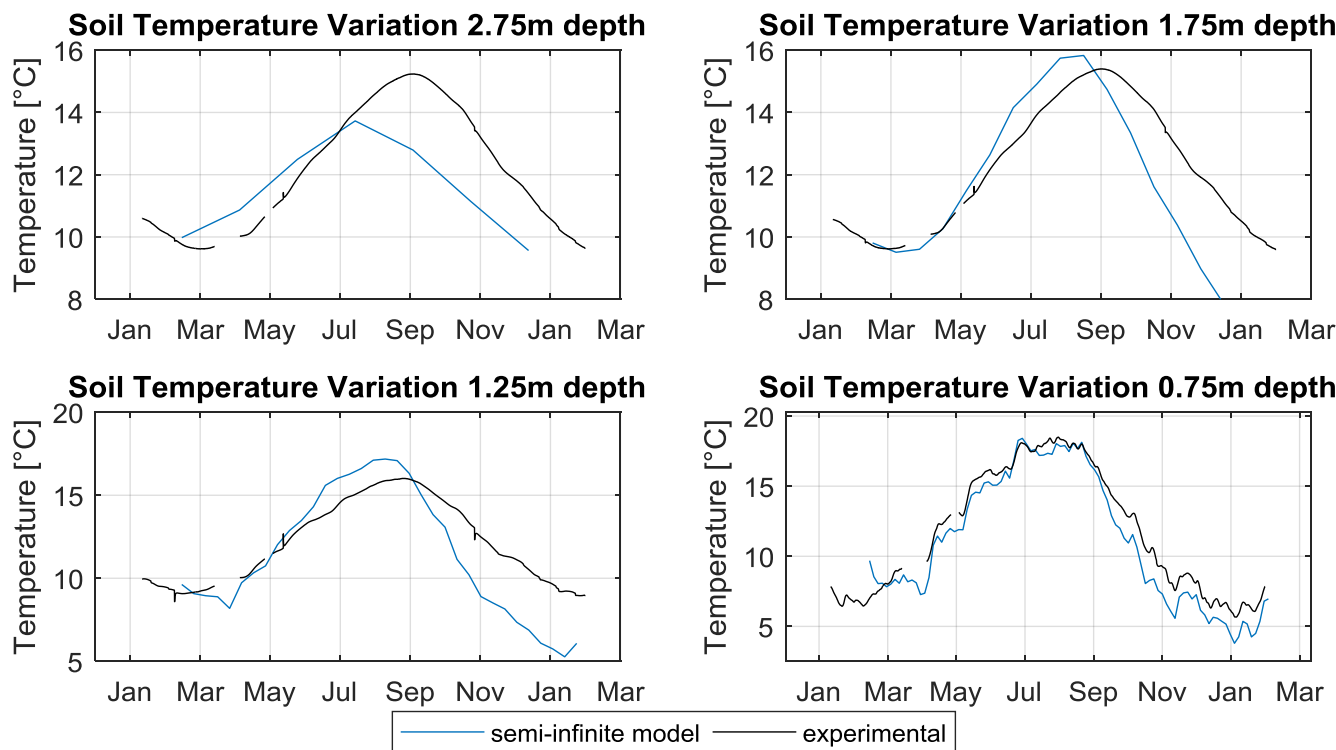

Figure 10. Comparison between the semi-infinite solid model and the experimental data

\subsection{Finite difference method assuming constant surface temperature FDM-T}

The FDM is a numerical method that can estimate, with sufficient precision, the diffusion of heat in the soil. In addition, this method is desirable for modelling because of its fast resolution and ease of integration with other types of dynamic system models. In this context, Figure 11 shows the comparison of the results of the modelled vs. actual variation of the soil temperature at different depths. In this method, constant surface temperature was considered as a boundary condition (FDM$\mathrm{T})$. The air temperature was approximated as the temperature of the soil surface. For ground covered with vegetation or grass this approach is justified. However, the energy balance at the soil surface must be solved to determine this temperature for other surfaces conditions. As shown in Figure 11, by this method the accuracy increases markedly, and the model is able to show the short-term thermal oscillations at shallow depths ( 0.75 metres). However, at depths of 1.25 and 1.75 metres the margin of discrepancy increases, especially in the cold months. This may occur due to the uncertainty in the consideration of the soil physical properties such as thermal diffusivity or the variation of the thermal conductivity as a function of temperature and water content, which might be more influential near the surface [35]. 

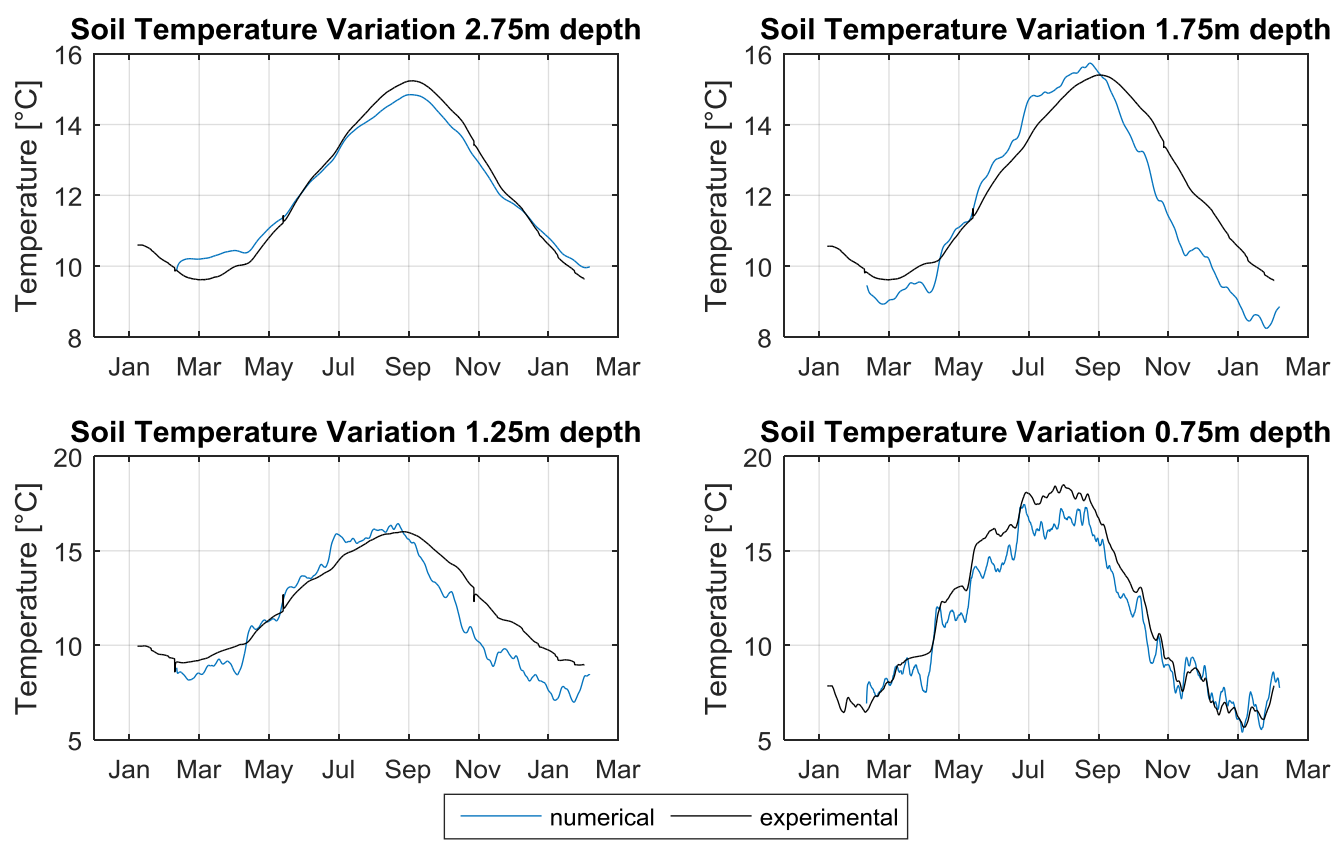

Figure 11. Comparison between the FDM-T and the experimental data

\subsection{Finite difference method assuming constant surface heat flux FDM-HF}

Figure 12 shows a comparison between experimental data and the predicted soil temperature variation at different depths using the FDM with constant heat flux (periodically variable) as a boundary condition (FDM-HF). This approach is more complex than the FDM-T as a larger number of inputs is required (solar radiation, air temperature, rainfall, wind speed, soil porosity, relative humidity, etc.) but it should be more accurate for soil that is covered with vegetation. However, Figure 12 shows that using this approach reduced accuracy compared to FDM-T. This is probably due to the consideration of heat transfer by evaporation and radiation, which increases uncertainty due to the inclusion of more input parameters. Some of these parameters such as the rainfall, solar radiation, wind speed and relative humidity were measured; however, others such as soil porosity, soil emissivity, soil absorptivity, convection coefficient and sky temperature were estimated or calculated. For all the depths considered the model underestimates the soil temperature variation. 

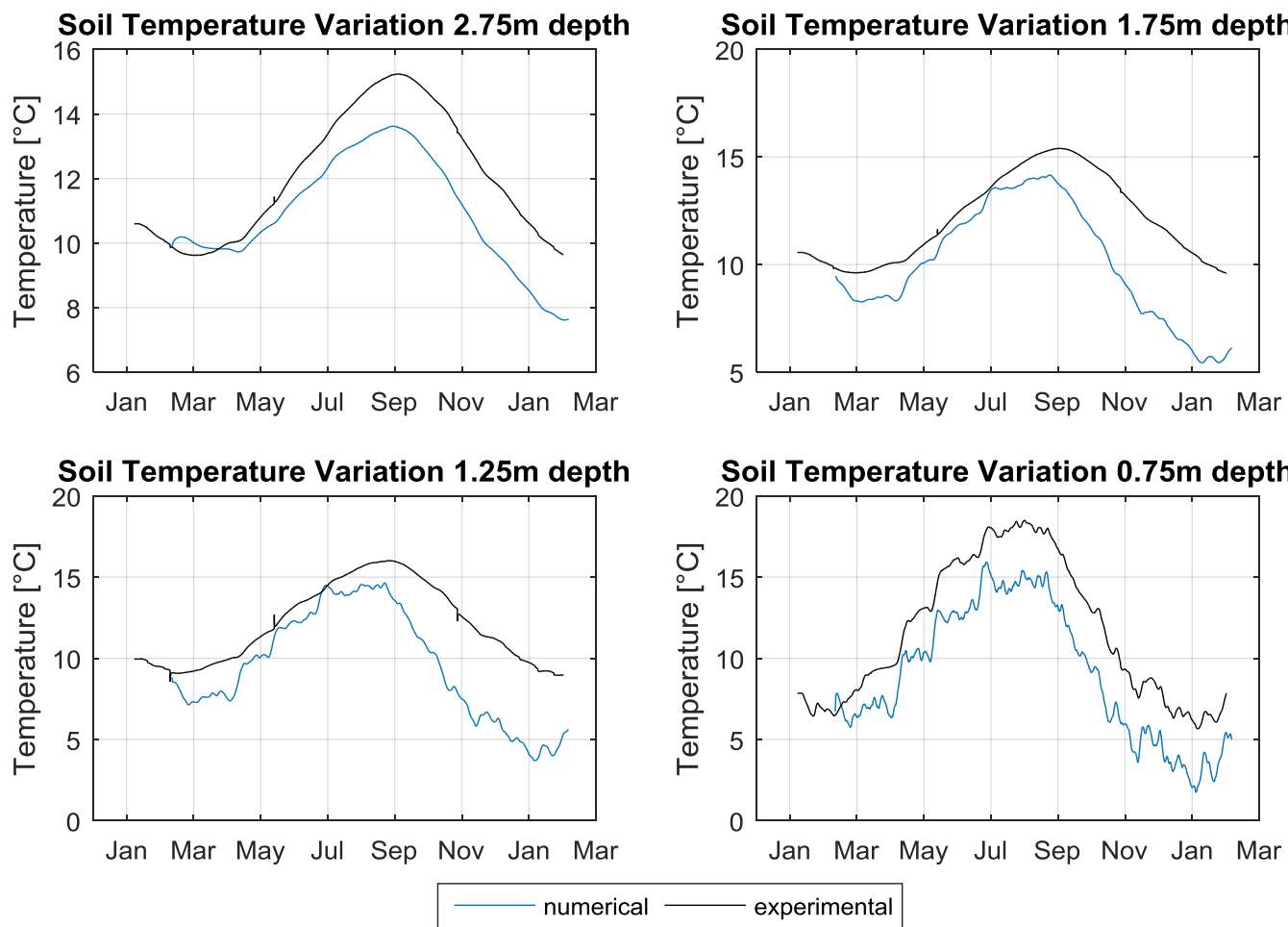

Figure 12. Comparison between the FDM-HF and the experimental data

\subsection{Accuracy of the different models}

In order to evaluate the accuracy of the different models from a statistical point of view, the coefficient of determination $\left(R^{2}\right)$, the root mean square error (RMSE) and the normalised root mean square error (NRMSE) were determined (Table 3). The four models show a high $\mathrm{R}^{2}$ at depths of 0.75 and 1.25 meters ranging from 0.74 to 0.99 . This means that the experimental values are in good agreement with the model predictions. The lowest $R^{2}$ values corresponds to the semi-infinite model at depths of $1.55 \mathrm{~m}$ $\left(R^{2}=0.55\right)$ and $2.75 \mathrm{~m}\left(R^{2}=0.36\right)$ while the highest correspond to the FDM-T at depths of $0.75 \mathrm{~m}$ $\left(R^{2}=0.98\right)$ and $2.75 \mathrm{~m}\left(R^{2}=0.99\right)$. However, it is worth noting that the coefficient of determination is not sufficient to show how well a model fits experimental data. For this reason, it is also important to determine the error between the model predictions and the experimental data. In this context, Table 3 shows that even if a model has a high coefficient of determination, the error may still be significant. For instance, for the sinusoidal model at a depth of $2.75 \mathrm{~m}$, the coefficient of determination is 0.98 ; however, the NRMSE is $135.86 \%$, which is high enough to make a model unacceptable. This error is mainly due to an overestimation of the undisturbed ground temperature, as seen in Figure 9. Regarding the semi-infinite model, the NRMSE at $0.75 \mathrm{~m}$ and $1.25 \mathrm{~m}$ are $12.11 \%$ and $25.99 \%$ respectively which is low enough to estimate the temperature variation of the shallow soil. Nevertheless, at greater depths, the error increases drastically up to $104.88 \%$ for a depth of $2.75 \mathrm{~m}$. This confirms the previous findings that the semi-infinite model lacks accuracy for deeper soil due to the low thermal penetration depth. With respect to the FDM-HF, it shows the highest error of all the evaluated models even though the $\mathrm{R}^{2}$ is not particularly low. Indeed, the NRMSE for the FDM-HF ranges from $42.94 \%$ to $163.68 \%$. This is mainly due to the large number of uncertainties in the input variables for this model such as soil emissivity, sky temperature, soil porosity, etc. On the other hand, the FDM-T model shows the best fit at the lowest depths $(0.75 \mathrm{~m}$ ) of all the models (NRMSE $=9.22 \%$ ). Hence, this model is a good approach for evaluating the short-term soil temperature behaviour and it can predict hourly temperature fluctuations, as shown in Figure 11. Nonetheless, the FDM-T model has not been tested under high vegetated soils or concrete or asphalt-covered soil. In these cases, the 
model might not be applicable because the surface temperature will be significantly different compared to the air temperature. As can be noted, all the models show less accuracy for medium depths ( $1.25 \mathrm{~m}$ and $1.75 \mathrm{~m}$ ). This may be due to a variation in the soil properties with depth. It is common to find that real soil has a different composition at different depths, causing a variation in the thermal properties. Likewise, it is worth considering in future research that the thermal conductivity and specific heat may vary over time due to the changing water content of the soil.

Finally, it is important to note that the computational time to solve the model for one year using hourly time steps by the numerical explicit method is 25 seconds for the FDM-T and 45 seconds for the FDM$\mathrm{HF}$ on a $3.2 \mathrm{GHz} 4$-core processors desktop computer. Hence, the use of the explicit method has a low computational cost for an annual simulation and it is suitable for integration into building simulation software.

Table 3. Statistical parameters of the different models

\begin{tabular}{lllll}
\hline Model & Depth $\mathbf{~}$ & $\mathbf{R}^{\mathbf{2}}$ & RMSE $^{\circ} \mathbf{C}$ & NRMSE $\%$ \\
\hline \multirow{4}{*}{ Sinusoidal } & 0.75 & 0.97 & 9.76 & 76.09 \\
& 1.25 & 0.94 & 8.68 & 116.96 \\
& 1.75 & 0.93 & 8.24 & 142.13 \\
& 2.75 & 0.98 & 7.62 & 135.86 \\
\hline \multirow{3}{*}{ Semi-infinite } & 0.75 & 0.97 & 1.54 & 12.11 \\
& 1.25 & 0.96 & 2.91 & 25.99 \\
& 1.75 & 0.55 & 4.94 & 37.78 \\
& 2.75 & 0.36 & 5.01 & 104.88 \\
\hline \multirow{4}{*}{ FDM-T } & 0.75 & 0.98 & 1.18 & 9.22 \\
& 1.25 & 0.87 & 1.99 & 28.14 \\
& 1.75 & 0.88 & 1.16 & 20.02 \\
FDM-HF & 2.75 & 0.99 & 0.10 & 1.82 \\
& 0.75 & 0.96 & 9.88 & 76.95 \\
& 1.25 & 0.74 & 11.56 & 163.68 \\
& 1.75 & 0.68 & 7.72 & 133.01 \\
& 2.75 & 0.83 & 2.41 & 42.94 \\
\hline
\end{tabular}

\section{Conclusions}

In this study, a comparison was conducted between different analytical and numerical models to predict the time varying soil temperature at different depths. Two analytical models and two numerical models were used to simulate the soil temperature and the results were compared with hourly experimental data from an urban location in Leicester, UK. The analytical sinusoidal model, despite its high coefficient of determination (more than 0.93 in average), has one of the highest errors due to the uncertainty on the actual value of the undisturbed ground temperature. Consequently, this model is not able to determine accurately the short-term temperature variations in shallow spoil (less than $2 \mathrm{~m}$ ). This uncertainty can be reduced easily with a modification on the input value of the undisturbed ground temperature. However, this parameter is commonly not measured by the weather stations and estimations models must be applied. The analytical semi-infinite model accurately determines the soil temperature variation at very shallow depths (a few centimetres) and it also models short-term fluctuations well. However, it lacks applicability for analysis at depths greater than one metre. Numerical models, despite their higher complexity, are able to show both short and long-term soil temperature variations. The FDM-T had the lowest error and has the benefit that in addition to soil properties, it only requires air temperature as an input parameter. The FDM-HF did 
not show high accuracy, which can be attributed to the uncertainty of the large number of input parameters required as rainfall rate, solar radiation, sky temperature, relative humidity, etc. The FDM$T$ is therefore chosen as a suitable model due to its high accuracy and relative simplicity. This model is able to perform fast simulations, which is desired for multi-year simulations. Additionally, unlike the sinusoidal model, the FDM-T does not have a high dependence on the value of the undisturbed ground temperature but on the ambient air temperature which reduces the uncertainty of the shallow soil temperature prediction. These findings are relevant for different research fields such as the study of shallow geothermal systems such as horizontal ground source heat pumps, mainly related to the short-term prediction of a geothermal system performance. The findings are also relevant for the study of the natural soil temperature variation which is a key topic in agriculture and climate analysis. As noted, the accuracy of the FDM-T can be improved by adding extra considerations such as variable thermal conductivity as a function of time and depth. This opens the door to future research. Likewise, other soils have different surface conditions such vegetation, asphalt or buildings, so future research is suggested to analyse the applicability of the model for other surface conditions and locations.

\section{Acknowledgements}

The authors of this publication gratefully acknowledge De Montfort University and The Zero Carbon Solution for the financial support in the conduct of this research project.

\section{References}

[1] S. D. Wullschleger, J. E. Cahoon, J. a Ferguson, and D. M. Oosterhuis, "Simulation of Soil Surface Temperature Using the Energy Balance Equation," J. Agron. Educ., vol. 20, no. 1, 1991.

[2] M. Singh, B. Sarkar, B. Biswas, N. S. Bolan, and G. J. Churchman, "Relationship between soil clay mineralogy and carbon protection capacity as influenced by temperature and moisture," Soil Biol. Biochem., vol. 109, pp. 95-106, 2017.

[3] S. Signorelli and T. Kohl, "Regional ground surface temperature mapping from meteorological data," Glob. Planet. Change, vol. 40, no. 3-4, pp. 267-284, Feb. 2004.

[4] L. Lamarche and B. Beauchamp, "A new contribution to the finite line-source model for geothermal boreholes," Energy Build., vol. 39, no. 2, pp. 188-198, 2007.

[5] M. H. Sharqawy, H. M. Badr, and E. M. Mokheimer, "Investigation of buoyancy effects on heat transfer between a vertical borehole heat exchanger and the ground," Geothermics, vol. 48, pp. 52-59, 2013.

[6] A. Bidarmaghz, G. A. Narsilio, I. W. Johnston, and S. Colls, "The importance of surface air temperature fluctuations on long-term performance of vertical ground heat exchangers," Geomech. Energy Environ., vol. 6, pp. 35-44, 2016.

[7] F. Droulia, S. Lykoudis, I. Tsiros, N. Alvertos, E. Akylas, and I. Garofalakis, "Ground temperature estimations using simplified analytical and semi-empirical approaches," Sol. Energy, vol. 83, no. 2, pp. 211-219, Feb. 2008.

[8] A. Shirvani, F. Moradi, and A. A. Moosavi, "Time series modelling of increased soil temperature anomalies during long period," Int. Agrophysics, vol. 29, no. 4, pp. 509-515, 2015.

[9] T. T. Chow, H. Long, H. Y. Mok, and K. W. Li, "Estimation of soil temperature profile in Hong Kong from climatic variables," Energy Build., vol. 43, no. 12, pp. 3568-3575, Dec. 2011. 
[10] T. Kusuda and P. Achenbach, "Earth temperature and thermal diffusivity at selected stations in the United States," 1965.

[11] F. P. Incropera, D. P. DeWitt, T. L. Bergman, and A. S. Lavine, Fundamentals of Heat and Mass Transfer, vol. 6th. John Wiley \& Sons, 2007.

[12] J. Charpin, T. Myers, A. Fitt, Y. Ballim, and A. Patini, "Modelling Surface Heat Exchanges From a Concrete Block Into the Environment," Math. Ind. Study Gr. South Africa, pp. 51-58, 2004.

[13] P. J. Cleall, J. J. Muñoz-Criollo, and S. W. Rees, "Analytical Solutions for Ground Temperature Profiles and Stored Energy Using Meteorological Data," Transp Porous Med, vol. 106, pp. 181-199, 2015.

[14] M. Badache, P. Eslami-Nejad, M. Ouzzane, Z. Aidoun, and L. Lamarche, "A new modeling approach for improved ground temperature profile determination," Renew. Energy, vol. 85, pp. 436-444, Jan. 2016.

[15] T. R. H. Holmes, T. J. Jackson, R. H. Reichle, and J. B. Basara, "An assessment of surface soil temperature products from numerical weather prediction models using ground-based measurements," Water Resour. Res., vol. 48, no. 2, Feb. 2012.

[16] T. Yilmaz, A. Özbek, A. Yilmaz, and O. Büyükalaca, "Influence of upper layer properties on the ground temperature distribution," J. Therm. Sci. Technol., vol. 29, no. 2, pp. 43-51, 2009.

[17] M. Chalhoub, M. Bernier, Y. Coquet, and M. Philippe, "A simple heat and moisture transfer model to predict ground temperature for shallow ground heat exchangers," Renew. Energy, vol. 103, pp. 295-307, 2017.

[18] A. Kenan Tezcan, "Formula for the calculation of ground temperature at $1 \mathrm{~m}$ depth in Turkey," Geothermics, vol. 21, no. 3, pp. 415-417, 1992.

[19] G. Hu et al., "An improved model for soil surface temperature from air temperature in permafrost regions of Qinghai-Xizang (Tibet) Plateau of China," Meteorol. Atmos. Phys., pp. 1-11, Jun. 2016.

[20] D. Zheng, E. R. Hunt, and S. W. Running, "A daily soil temperature model based on air temperature and precipitation for continental applications," Clim. Res., vol. 2, no. 1, pp. 183191, 1993.

[21] K. Dolschak, K. Gartner, and T. W. Berger, "A new approach to predict soil temperature under vegetated surfaces," Model. Earth Syst. Environ., vol. 1, no. 4, p. 32, Dec. 2015.

[22] H. Tabari, P. Hosseinzadeh Talaee, and P. Willems, "Short-term forecasting of soil temperature using artificial neural network," Meteorol. Appl., vol. 22, no. 3, pp. 576-585, Jul. 2015.

[23] R. G. Allen, L. S. Pereira, D. Raes, and M. Smith, "Crop evapotranspiration: Guidelines for computing crop water requirements," in FAO, Food and Agriculture Organization of the United Nations, 1998, p. 300.

[24] D. G. Krdgerl, "Convection heat transfer between a horizontal surface and the natural environment," Res. Dev. J., vol. 18, no. 3, pp. 49-54, 2002.

[25] TRNSYS, "A transient system simulation program." Solar Energy Laborataory, University of Wisconsin--Madison, 2010.

[26] Canmet Energy, "RETScreen International. Clean Energy Project Analysis," no. Third Edition. Minister of Natural Ressources Canada, 2005. 
[27] DOE-2.3, "Building Energy Use and Cost Analysis Tool." Berkeley, CA (United States), 01-Nov2016.

[28] US Department of Energy, "EnergyPlus Engineering Reference: The Reference to EnergyPlus Calculations," US Department of Energy. pp. 1-847, 2010.

[29] G. Florides and S. Kalogirou, "Annual Ground Temperature Measurements at Various Depths," 8th REHVA World Congr., no. May 2016, 2005.

[30] K. Roth, Soil Physic: Lecture Notes, First. Institute of Environmental Physics, Heidelberg University, 2012.

[31] M. Ouzzane, P. Eslami-Nejad, M. Badache, and Z. Aidoun, "New correlations for the prediction of the undisturbed ground temperature," Geothermics, vol. 53, pp. 379-384, 2015.

[32] G. Soriano et al., "Thermal geological model of the city of Guayaquil, Ecuador," Geothermics, vol. 66, pp. 101-109, 2017.

[33] Department of Energy and Climate Change, "MCS 3005-1: Microgeneration installation standard: MCS 022 Ground heat exchanger look-up tables: Supplementary material to MIS 3005: Issue 1.0." 2011.

[34] V. Soldo, S. Borović, L. Lepoša, and L. Boban, "Comparison of different methods for ground thermal properties determination in a clastic sedimentary environment," Geothermics, vol. 61, pp. 1-11, 2016.

[35] D. Arias-Penas, M. P. Castro-García, M. A. Rey-Ronco, and T. Alonso-Sánchez, "Determining the thermal diffusivity of the ground based on subsoil temperatures. Preliminary results of an experimental geothermal borehole study Q-THERMIE-UNIOVI," Geothermics, vol. 54, pp. 3542, 2015. 